\title{
Abordagem sistêmica do design em microempresas e empresas de pequeno porte no Alto Vale do Itajaí com foco em inovação e sustentabilidade
}

\author{
Luiz Fernando Gonçalves de Figueiredo; \\ Eliete Auxiliadora Assunção Ourives; \\ Carina Scandarola da Silva; \\ Isabel Cristina Moreira Victoria.
}

\section{resumo:}

A visão sistêmica do design contribui para que os processos de gestão de design se tornem mais sustentáveis. A sustentabilidade não apenas é necessária, mas uma condição da continuidade e alinhamento da profissão com as preocupações atuais. Neste contexto, a pesquisa teve como objetivo fazer um estudo de caso, avaliando a gestão de design em Microempresas e Empresas de Pequeno Porte do Alto Vale do Itajaí, com base em uma abordagem sistêmica, com a finalidade de orientá-las para a sustentabilidade e inovação. Para isso, teve-se como intensão realizar a pesquisa fazendo uma imersão no contexto, coletando informações por meio de ferramentas que possibilitam a visão sistêmica das organizações. Por meio dos resultados de pesquisa poderão ser extraídos os indicadores de ponto onde a gestão de design deve se tornas mais sustentável e com inovação dentro das empresas de pequeno porte do Vale do Itajaí.

palavras-chave:

design; sustentabilidade; abordagem sistêmica; gestão; inovação. 


\section{Introdução}

Os mais conhecidos discursos políticos e sociais sobre sustentabilidade estão associados a preservação e conservação e, ao contrário disso, na concepção de Manzini (2008), caminhar rumo a sustentabilidade é o contrário da conservação. Em outras palavras, a preservação e a regeneração de nosso capital natural ambiental e social significará romper com as tendências dominantes em termos de estilo de vida, produção e consumo, criando e experimentando novas possibilidades. Tendo em vista estas novas possibilidades, esta pesquisa vai procurar atender esta demanda de ações orientadas para a sustentabilidade com o objetivo maior de utilizar nossos recursos ambientais, sociais e econômicos sem comprometer a capacidade de recuperação do sistema e sem comprometer as oportunidades das gerações futuras. É nesta linha que esta pesquisa visa trabalhar, na busca por um design voltado para a sustentabilidade, com uma temática que envolve a gestão de design em empresas de design.

O tema da pesquisa trata sobre a avaliação com abordagem sistêmica da gestão de design em Microempresas e Empresas de Pequeno Porte - MPEs de design com o objetivo de orientá-las para a sustentabilidade. Através da aplicação de método de avaliação existente adaptado ao contexto da gestão de design e da sustentabilidade identificou indicadores para implementação de inovações para a sustentabilidade na gestão de design.

Com a pesquisa foi possível avaliar a situação da sustentabilidade na gestão de design de uma microempresa tendo sempre como foco uma visão sistêmica de sua atuação, com os indicadores de sustentabilidade obtidos pela avaliação possibilitou dar ênfase aos pontos mais fracos da gestão e ampliar o sistema nos pontos onde havia maior deficiência de atuação da gestão de design para a sustentabilidade. Com uma visão macro dos pontos mais fracos, eles foram tratados de forma individual e cuidadosa para a busca de implementações de inovações na gestão de design com a finalidade de orientá-la a tornar-se socialmente, economicamente e ambientalmente sustentável, sob uma perspectiva sistêmica.

O principal problema que motiva esta pesquisa é a falta de uma ferramentas e embasamento para avaliação da sustentabilidade na gestão de design, tendo uma perspectiva sistêmica do processo, para conhecer com mais profundidade os problemas e implementar soluções mais eficazes e orientadas para a sustentabilidade.

\section{Metodologia}

O Guia Projetual NAS DESIGN foi desenvolvido pelo Núcleo de Abordagem Sistêmica do Design (NAS Design), que é um laboratório acadêmico pertencente ao Departamento de Expressão Gráfica, localizado no Centro de Comunicação e Expressão da Universidade Federal de Santa Catarina em Florianópolis. O método consiste em "uma abordagem sistêmica, onde o design é entendido como um processo holístico, e, dessa forma, o foco é deslocado do produto final para o sistema produtivo e suas complexas interações" (AROS, 2016, p. 46).

Esse método consiste em três fases: "Sentir", "Agir" e "Realizar". A fase "Sentir" é o primeiro contato com a comunidade, em que define-se a problematização e ocorrem as primeiras conversas e experiências com a comunidade estudada, coletando informações e conteúdo para o projeto. A segunda fase é "Agir", nela busca-se desenvolver soluções tangíveis, com o apoio e participação do público-alvo. A terceira fase é "Realizar", e fundamenta-se em implementar o produto final e dar suporte à comunidade se necessário. Assim como explicado na Figura 1. 


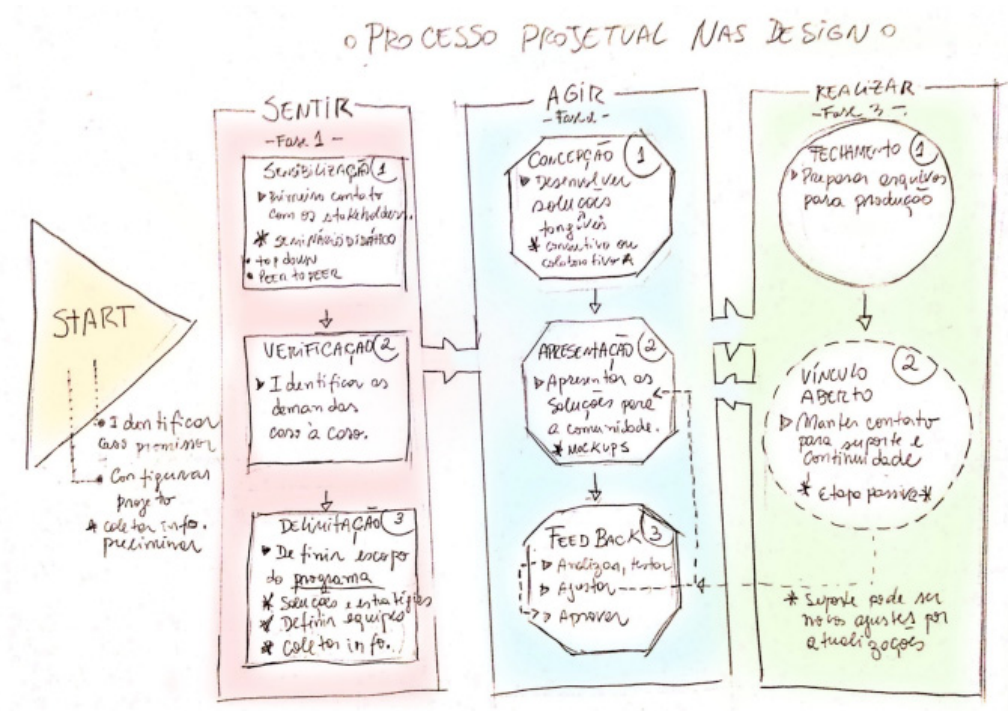

Figura 1 - Detalhamento dos processos do Guia Projetual NAS DESIGN. Fonte: AROS, 2016, p. 58

A primeira etapa do método consiste em fazer observações e acumular informações sobre o público com o qual se trabalhará. Segundo Aros (2015) a abordagem com o público se dá de forma empática, compreendendo a realidade do público e reunindo informações necessárias para as próximas fases. Ao final dessa etapa tem-se o alinhamento de informações e entendimento do que o público estudado precisa (identidade gráfica, produto, organizações).

Após fazer o planejamento, coletar informações e sintetizar os dados levantados inicia-se a fase criativa. Segundo Aros (2015) essa fase tem o objetivo de prospectar soluções. As ferramentas utilizadas nesse processo são referentes à criatividade e podem ser adicionadas outras ferramentas se essa for a demanda do projeto em andamento. O desenvolvimento dessa etapa foi feito de forma colaborativa com o público-alvo.

A terceira etapa marca a finalização e fechamento do projeto, onde é determinada a solução final e detalhamentos gerais do projeto.

\section{Sustentabilidade}

O conceito de sustentabilidade abordado está dividido nos âmbitos ambientais, sociais e econômicos. A sustentabilidade ambiental, de acordo com Manzini (2008) refere-se às condições sistêmicas a partir das quais as atividades humanas, em escala mundial ou em escala local, não perturbem os ciclos naturais além dos limites de resiliência dos ecossistemas nos quais são baseados e, ao mesmo tempo, não empobreçam o capital natural que será herdado pelas gerações futuras.

A sustentabilidade social, refere-se às condições sistêmicas através das quais, seja em escala mundial ou regional, as atividades humanas não contradizem os princípios da justiça e da responsabilidade em relação ao futuro, considerando a atual distribuição e a futura disponibilidade de espaço ambiental.

O conceito de sustentabilidade econômica frequentemente é esquecido. De acordo a Rede Nacional de Consumo Responsável (2009) os recursos econômicos têm de ser preservados, assim como o espaço de manobra para as gerações futuras. Além do mais, a sustentabilidade ecológica só pode ser alcançada por sociedades que desenvolvam comportamentos economicamente sustentáveis. Os princípios da sustentabilidade econômica residem sobretudo:

- na organização de estruturas econômicas de longo prazo que devem responder às exigências de sistemas estáveis;

- na preservação do capital real, como infraestruturas e edifícios;

- na estabilização do valor monetário, prevenindo a inflação;

- no fato dos custos dos benefícios e serviços deverem ser pagos pela geração que deles beneficia; 
- na restrição parcial ou total do endividamento, pois cada geração deve pelo menos preservar o seu próprio capital real recebido da geração dos seus pais e passá-lo à geração seguinte;

- no uso eficaz dos recursos;

- na garantia de todos os serviços econômicos deverem ser produzidos de forma transparente e tendo em conta todas as despesas;

- no fato de os impostos pagos por cidadãos e empresas deverem ser orientados para a sua capacidade de pagamento;

- na negociação de pactos intergeracionais justos, que não coloquem em desvantagem as gerações futuras.

Kazazian (2005) resume estas questões da seguinte forma

O crescimento econômico a qualquer preço, que hipnotiza obsessivamente numerosos peritos e decisores, está com os dias contados: a geração de novos empregos em que se baseia é um dividendo que por enquanto não se realizou; a repartição das riquezas por ele gerada aumenta mais do que reduz as desigualdades, e deve se constatar que os recursos naturais que o alimentam não são infinitos, devendo alguns esgotar-se antes do fim deste século. (KAZAZIAN; 2005:8)

A dependência dos princípios econômicos, sociais e ambientais mostra que apesar da grande preocupação existente em relação aos impactos ambientais que o planeta vem sofrendo, percebe-se a solução não será apenas a conservação do capital natural, vai ser necessário pensar em fatores de como distribuição de renda, direitos humanos, educação e muitos outros para iniciar um processo em direção a sustentabilidade das atividades humanas no planeta.

\subsection{Empresa sustentável}

A empresa como "unidade de organização dedicada a atividades industriais, comerciais ou de prestação de serviços com fins lucrativos" vem sendo o ponto central do poder empresarial e a fonte de riqueza das nações, BCSD (2007). Nesta definição é dada à empresa um papel meramente lucrativo, este conceito está sujeito a alteração com base na alteração da situação atual, que trouxe consigo a análise da posição empresarial relativa às economias mundiais e ao seu papel no crescimento econômico e social dos países.

Isso aconteceu porque, de acordo com o BCSD (2007), o foco dos gestores evoluiu, durante a segunda metade do século XX, da atenção única do desejo dos acionistas em aumentar os seus dividendos para a necessidade de contar com as regras do meio onde uma legislação, cada vez mais madura, faz com que as empresas não se apropriem de forma oportunista dos recursos adjacentes. Nos últimos anos, as empresas estão conscientes da necessidade de prestar contas sobre o seu comportamento a novos detentores do capital das mesmas. Nesta situação, o julgamento da opinião pública é implacável e diário. Atualmente, clientes, trabalhadores, administradores, fornecedores, etc. com múltiplas fontes de informação avaliam o comportamento e atuam em consequência disso. As suas decisões fazem parte do valor da empresa.

De acordo com o World Business Council for Sustainable Development (2009), para que se mantenham os empreendimentos de sobrevivência sustentável, um termo que se expressa na atuação da empresa e no desenvolvimento de suas principais capacidades. O termo indica que os princípios empresariais tradicionais deverão ser mantidos, por serem essenciais para o sucesso de modelos de sobrevivência sustentável, porém uma nova visão sobre esses princípios deverá ser configurada. Assim, o WBCSD (2009) sugere que negócios com sobrevivência sustentável sejam conduzidos pela realização de ações incrementadoras (manter o foco, estabelecer parcerias e identificar). 


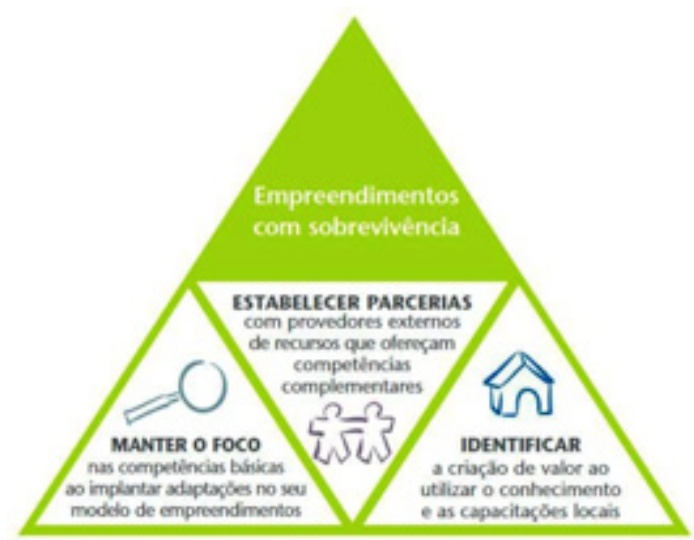

Figura 2: As fundações sólidas de empreendimentos com sobrevivência sustentável - Fonte:WBCSD, 2009

No design, Datschefski (2001) defende que o desenvolvimento de produtos sustentáveis depende dos 5 princípios de definidos por ele como:

- Cíclico - O produto é feito de materiais orgânicos compostáveis ou de minerais que são continuamente reciclados em um círculo fechado.

- Solar - O produto na manufatura e uso consuma somente energia renovável que seja cíclica e segura.

- Segurança - Todos os resíduos para o ar, água ou ambiente sirvam de comida para outros sistemas.

- Eficiência - O produto em manufatura e uso requer 90\% menos energia, materiais e água do que produtos com a mesma utilidade em 1990.

- Social - Produto em manufatura e em uso respeita os direitos humanos e a justiça natural.

Estes princípios são uma forma de direcionar a atividade para melhorar a performance dos produtos e serviços concebidos dentro da atividade da gestão de design na empresa de design.

\subsubsection{Indicadores de sustentabilidade}

Indicador é definido pela OCDE (2002) como um parâmetro, ou valor derivado de parâmetros, que indica, fornece informações ou descreve o estado de um fenômeno área/ambiente, com maior significado que aquele apenas relacionado diretamente ao seu valor quantitativo. Também considera que o indicador é uma ferramenta de avaliação entre outras; para captar-se todo o seu sentido, devem ser interpretados de maneira científica e política. Devem, com a devida frequência, ser completados com outras informações qualitativas e científicas, sobretudo para explicar fatores que se encontram na origem de uma modificação do valor de um indicador que serve de base a uma avaliação"

De acordo com o BCSD (2007) os sistemas de indicadores de sustentabilidade na empresa têm como primeiro objetivo disponibilizar informação útil para os processos de tomada de decisão e de prestação de contas sobre aspectos chave da empresa relacionados com as suas responsabilidades relevantes para a sustentabilidade.

Nesta pesquisa, após a avaliação da gestão de design na MPE de design foram obtidos os indicadores de sustentabilidade. Com eles tem-se a possibilidade de verificar as áreas que necessitam maior concentração de esforços para implementar ações inovadoras e melhorias na sua forma de atuação, com foco na sustentabilidade.

\section{Abordagem sistêmica do design}

A abordagem sistêmica como conceito, sob o ponto de vista de Chiavenato (1993), é a ênfase da teoria moderna sobre o dinâmico de interação que ocorre dentro da estrutura de uma organização. Esta abordagem contrasta com a visão clássica que enfatiza quase que somente a estrutura estática. A moderna teoria não desloca a ênfase na estrutura, mas simplesmente adiciona a ênfase sobre o processo de interação entre as partes que ocorre dentro da estrutura. Andrade et al (2006) fala que a adoção de abordagens sistêmicas na teoria organizacional e nas ciências relacionadas com administração vincula-se estreitamente ao crescimento da complexidade das organizações humanas, o 
qual trouxe a necessidade de melhorar a capacidade de administrar e solucionar problemas cada vez mais complexos. Isso fez se constituir um ambiente cada vez mais favorável à adoção de ideias sistêmicas na administração de organizações sociais e de produção.

A abrangência das tarefas e objetivos do design está aumentando, conforme as definições mais atuais da atividade. Tendo isso em vista, Krucken (2009) afirma que o principal desafio do design atualmente é desenvolver ou suportar o desenvolvimento de soluções para questões de alta complexidade, que exigem uma visão abrangente do projeto, envolvendo produtos, serviços e comunicação de forma conjunta e sustentável. Na tabela abaixo, a autora faz uma síntese da perspectiva sistêmica do projeto e do papel do design.

\begin{tabular}{|l|l|}
\hline \multicolumn{2}{|l|}{ Perspectiva sistêmica do projeto } \\
\hline $\begin{array}{l}\text { Características do } \\
\text { contexto }\end{array}$ & Complexidade e incerteza \\
\hline $\begin{array}{l}\text { Características do } \\
\text { projeto }\end{array}$ & Dinâmico, aberto a novos eventos \\
\hline Foco & $\begin{array}{l}\text { Sistemas de produtos e serviços } \\
\text { Diversidade, flexibilidade, sustentabilidade, } \\
\text { conectividade, interatividade }\end{array}$ \\
\hline Valores & Distribuída ou coletiva \\
\hline Autoria do projeto & Ator que coproduz valor e faz parte do inovação \\
\hline Papel do usuário & $\begin{array}{l}\text { Facilitar e apoiar a colaboração e o desenvolvimento de } \\
\text { inovações coletivas e sistêmicas }\end{array}$ \\
\hline Papel do designer & $\begin{array}{l}\text { Interlocução, capacidade de análise simbólica, } \\
\text { capacidade de desenvolver relações transversais na } \\
\text { sociedade, habilidade de escuta e de ação em diferentes } \\
\text { contextos, capacidade de integração de conhecimentos } \\
\text { de diversas áreas. }\end{array}$ \\
\hline $\begin{array}{l}\text { Competências } \\
\text { necessárias }\end{array}$ \\
\hline
\end{tabular}

Tabela 1 - Perspectiva sistêmica do projeto e o papel do designer. Fonte: KRUCKEN, 2009:45

$\mathrm{Na}$ área do design, conforme Bistagnino (2009), a abordagem linear do design emerge da atenção projetual limitada à construção de produtos e serviços que, de forma pontual, respondem às exigências do mercado, criando uma série de novas possibilidades. Essa abordagem não permite considerar os sistemas de valores sociais, culturais e éticos que constituem a verdadeira essência do produto ou do serviço e que reconstituem dignidade ao projeto dos bens. Para o autor, a abordagem sistêmica do design permite, portanto, alargar as referências, não se limitando ao produto. $\mathrm{O}$ foco do projeto se alarga para o conjunto de relações geradas e para a identificação dos fluxos de matéria e energia, que constituem a entrada e a saída do processo como um todo produtivo, comunicativo e social. A base da abordagem sistêmica é cercar-se da natureza e das suas dinâmicas de funcionamento. O homem é parte da natureza e pode observá-la e imitá-la. Hoje, mais do que nunca, é necessário considerar essa eficiência dos materiais nos processos e a complexidade e necessidade das relações.

Nesta pesquisa, a abordagem sistêmica vai contribuir para visualizar um panorama holístico, entendendo a organização a ser estudada como um sistema aberto, aonde as interferências ou problemas detectados podem ser de ordem ambiental, social ou econômica relativos a interferências e relações internas e externas à organização e ao sistema de gestão de design. Os atores sociais envolvidos, sendo esta uma pesquisa de ordem social, são a maior fonte de informação para o delineamento de um panorama e para a avaliação da gestão de design extraindo indicadores para introdução de melhorias e inovações no processo de gestão de design com foco na sustentabilidade.

Para isso, a linguagem sistêmica é um dos instrumentos utilizados para colocar em prática as ideias sistêmicas. Desta forma, para pensar e utilizar uma abordagem sistêmica, de acordo com Andrade et al (2006), deve-se buscar uma linguagem que satisfaça nossas necessidades de pensar sistematicamente:

- que leve a pensar mais no todo do que nas partes;

- que enfatize mais os relacionamentos do que os objetos;

- que promova o entendimento da realidade mais como redes do que como hierarquia; 
- que permita ver círculos maiores de causalidade, em vez de cadeias lineares de causa e efeito;

- que focalize a dinâmica, os processos subjacentes, em vez da estrutura estática;

- que faça deixar de pensar e conceber o mundo como uma máquina, e permita ver o mundo como um organismo vivo.

Em resumo, uma linguagem que permita ler, conceituar e comunicar sobre a crescente complexidade e mudança do nosso mundo.

\section{Inovação para sustentabilidade}

No contexto da sustentabilidade a inovação tem um papel importante, estar com o olhar voltado para as necessidades atuais, mas sem criar produtos/serviços que irão comprometer as futuras gerações, assim como estar em busca de soluções de melhorias que busquem reduzir os impactos sobre o ambiente social, econômico e social. Conforme o BCSD (2005), a inovação deve ser pensada e planejada como alavanca do desenvolvimento sustentável, isto é, deve considerar não só os fatores econômicos, mas também os fatores ambientais e sociais, de modo a não comprometer o futuro das sociedades e, conseqüentemente, das organizações. Além disso, a inovação com foco no desenvolvimento sustentável pode gerar uma nova maneira de garantir a subsistência dos indivíduos, desenvolvendo novos processos de trabalho e novas maneiras de subsistência da sociedade.

Por outro lado, Bettina Von Stamm (2008) cita as pressões que as empresas sofrem por dois lados. Primeiramente, os governos vêm introduzindo uma série de novas leis, normas e regulamentações com o objetivo de proteger e resguardar o meio-ambiente. Segundo, os consumidores estão ficando cada vez mais ambientalmente conscientes. Mesmo se uma boa parte dos consumidores brasileiros ainda não está disposta a pagar mais caro por um produto igual, mas ecologicamente correto, o número de consumidores conscientes está aumentando e o volume de vendas desses produtos cresce bem mais que a média. Portanto, não são apenas as pressões externas que estão levando os gestores a buscarem inovações sustentáveis, mas o objetivo principal é tornarem suas empresas conhecidas como socialmente responsáveis, o quê é hoje uma grande tendência e um dos pontos fortes na governança corporativa.

Para Krucken (2009) a inovação para sustentabilidade também requer um alto grau de participação social. Para promover a concepção e soluções sustentáveis é necessário desenvolver uma visão sistêmica e integrar competências de diversos atores.

É no contexto do desenvolvimento sustentável dos processos de trabalho da gestão de design que busca-se atuar nesta pesquisa. Junto aos atores do processo de gestão de design, avaliar o ambiente e o processo de gestão de design para alcançar novas formas de atuação e implementações de pequenas ações na gestão de design com foco na sustentabilidade. Algumas pequenas ações dentro deste contexto que podem gerar grandes impactos, dentro do processo da pesquisa, na faze inicial antes mesmo de fazer uma avaliação mais aprofundada já pode-se perceber pequenos problemas que interferem na gestão de design. Dentro do campo a ser pesquisado, na fase exploratória e de reconhecimento do ambiente foi identificado alguns problemas internos como ruídos que dificultam a comunicação (equipamentos eletrônicos e telefones), a falta de uma ferramenta estruturada para gestão dos projetos de design e a falta de organização para dar um destino adequado aos resíduos que são gerados na atividade etc. Com estes itens já identificados, no processo da pesquisa-ação, junto ao grupo de pesquisa nos seminários que veremos a seguir é que serão tomadas decisões sobre alguma interferência no processo de gestão e qual tipo de ação será realizada.

As temáticas abordadas na fundamentação teórica para esta pesquisa foram desenvolvidas com a finalidade de colaborar para o seu desenvolvimento. A abordagem sistêmica na avaliação da gestão de design vai proporcionar um olhar abrangente para tentar encontrar soluções aos "problemas" que serão identificados no sistema formado pela gestão de design dentro da empresa. Observando e avaliando estas problemáticas pode-se encontrar suas origens tanto no próprio sistema formado pela gestão de design, assim como, em outros sistemas com os quais ela está inter-relacionada. A ordem destes problemas pode ser de responsabilidade da própria gestão de design deficiente, como também de outros sistemas externos que a estejam influenciando durante suas relações de interação. Tendo em vista que a abordagem sistêmica na avaliação da gestão de design tem o objetivo de direcioná-la para a sustentabilidade e sendo a sustentabilidade envolve fatores de ordem global (econômicos, sociais e ambientais), a visão na pesquisa para a sustentabilidade com esta abordagem abrangente (sistêmica) 
contribui para melhor entender e resolver a problemática. Esta avaliação da gestão de design com foco na sustentabilidade vai resultar nos indicadores de sustentabilidade que servirão de diretrizes para a implementação de inovação com foco na sustentabilidade, a inovação é uma etapa posterior a pesquisa, mas é um dos objetivos maiores a serem alcançados. O alcance dos objetivos depende de um estruturado procedimento metodológico, conforme pode-se conferir a seguir.

\section{Caso famílias do Alto Vale}

As comunidades constituídas por famílias no Alto Vale do Itajaí, Santa Catarina, Brasil, são caracterizadas pela ascendência europeia, principalmente de origem alemã e italiana. São grupos de pessoas que moram em pequenas e médias extensões de terra e vivem de produção artesanal e manufaturada de produtos como geleia, macarrão, mel, galinha, melado, biscoito, arroz. Normalmente, os filhos dessas famílias moram junto com elas e auxiliam na produção até certo momento, quando então, mudam-se para cidades vizinhas maiores em busca de emprego e educação. (Figura 3).

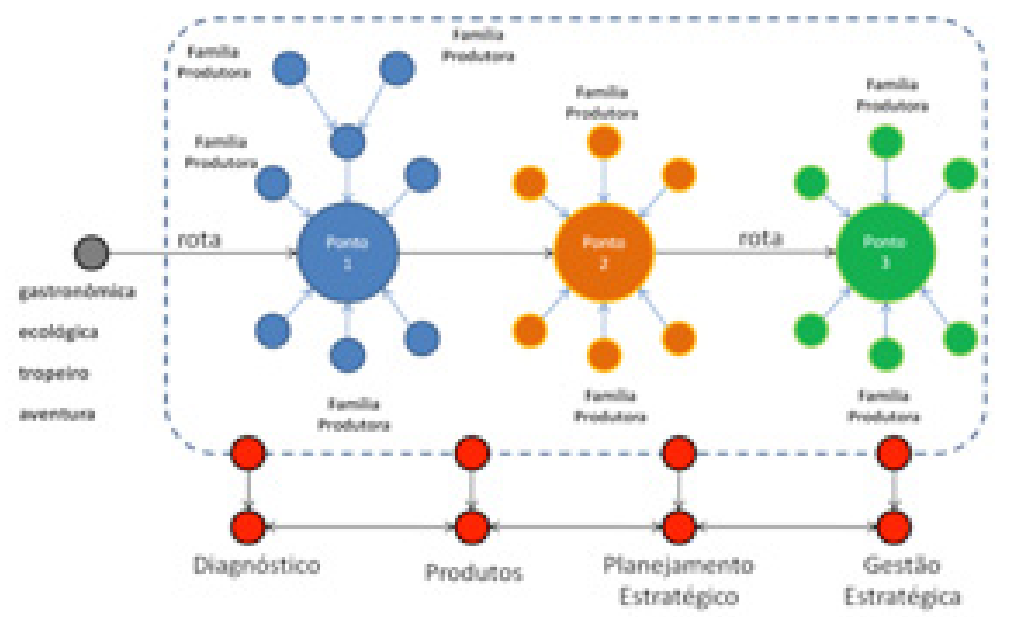

Figura 3 - Arranjo sistêmico percebido no Alto Vale. Fonte: NASDESIGN (2013).

O Alto Vale do Itajaí é uma região localizada no centro de Santa Catarina, sendo Rio do Sul seu principal município (Figura 4). A produção de produtos artesanais envolve a família como um todo, havendo divisão de tarefas entre homens e mulheres. Com o intuito de ilustrar o processo de design em estágio mais avançado, optou-se por comentar sobre três famílias e suas produções localizadas no município de Agronômica, no Alto Vale do Itajaí: Bork\&Grünfeldt, Fanton e Cattoni.

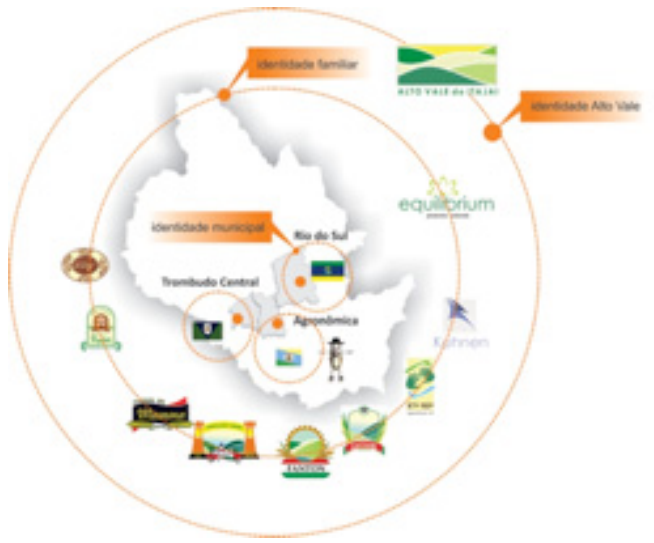

Figura 4 - Onde atuamos e Em busca da identidade do Alto Vale.. Fonte: NASDESIGN (2013).

A família Bork\&Grünfeldt é o resultado da união das duas famílias (ambas alemãs) que constituem seu nome, dando continuidade a uma produção conjunta de: geleias de laranja, figo, pêssego, nata, macarrão, nhoque, ovos de páscoa, mel, conservas (pepino) e galinha caipira. Já a família Fanton, tem origem italiana e se ocupa da produção de melado, rapadura, açúcar mascavo, 
cana de açúcar, doce de banana, doce de tangerina, biscoitos e comida colonial. Por fim, também de origem italiana, a família Cattoni se ocupa da produção de arroz e mel.

A Associação das Micro e Pequenas Empresas do Alto Vale do Itajaí (AMPE) é a ONG que indicou essas famílias para um trabalho conjunto com o NASDESIGN. Antes da chegada do grupo de pesquisa, já se desenvolvia o projeto Acolhida na Colônia, integrado à rede francesa AccueilPaysan, que propõe a valorização do modo de vida no campo por meio do agroturismo ecológico. No entanto, o projeto era realizado num sentido top-down, motivando as pessoas a atingirem certos padrões de qualidade para ganhar o selo de participação da rede, além de pagar uma quantia mensal para poder participar. Se por algum motivo, a família perdesse a possibilidade de colocar o selo em seus produtos, apenas ficava a frustração de não ter alcançado as metas de qualidade.

O objetivo do NASDESIGN consistiu em fortalecer a identidade dessas famílias, por meio do Processo de Design Habilitante para Iniciativas Locais, a fim de melhorar o posicionamento de seus produtos no mercado local e valorizar as raízes de suas tradições locais. Com este processo, foi possível construir vivências junto às comunidades, no intuito de interpretar características subjetivas que representavam as experiências dessas famílias, em seus valores e estética. O resultado foi a conformação de identidade visual para todas, como um brasão da produção familiar, o que trouxe motivação social e sentimento de pertencimento, além da maior aceitação às práticas de design. Com esta abertura, fica muito mais fácil inserir outros tipos de programas sociais, como a inserção de novos serviços, interfaces e ferramentas que melhor organizam as produções a uma realidade sustentável.

A identidade do Alto Vale do Itajaí (Figura 4) foi criada com o intuito de dar unidade ao conjunto de famílias que se identificam com suas marcas próprias, mas que também procuram fazer parte de um conjunto maior. Isto facilita o entendimento da formação do grupo com a mesma identidade, o que dá o sentimento de pertencimento às famílias e facilita a relação entre as pessoas em troca de serviços futuros.
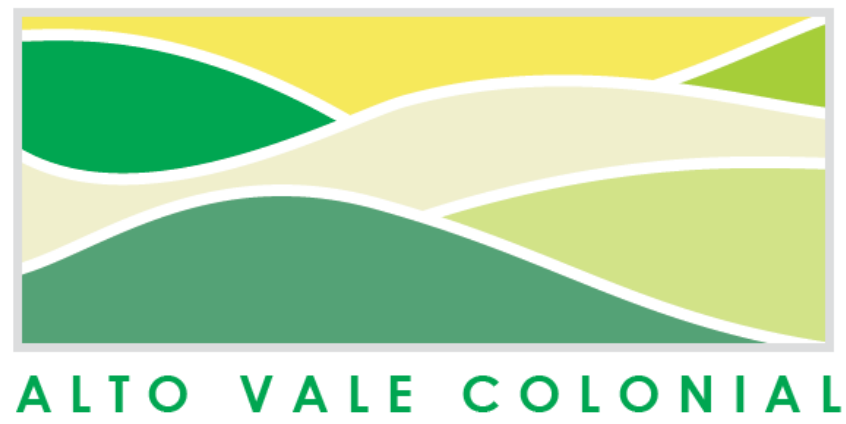

Figura 4 - Identidade do Alto Vale do Itajaí. Fonte: NASDESIGN (2013).

O desenvolvimento das marcas para as famílias Bork\&Grünfeldt, Fanton, Cattoni, e a embalagem para o arroz (Figura 5), Chocolate Franz (Figura 6), seguiu o mesmo princípio, de criar identidade visual a partir das experiências de convívio dos designers junto às comunidades com o intuito de representar, promover a unidade familiar e transpor os valores da família para seus produtos.

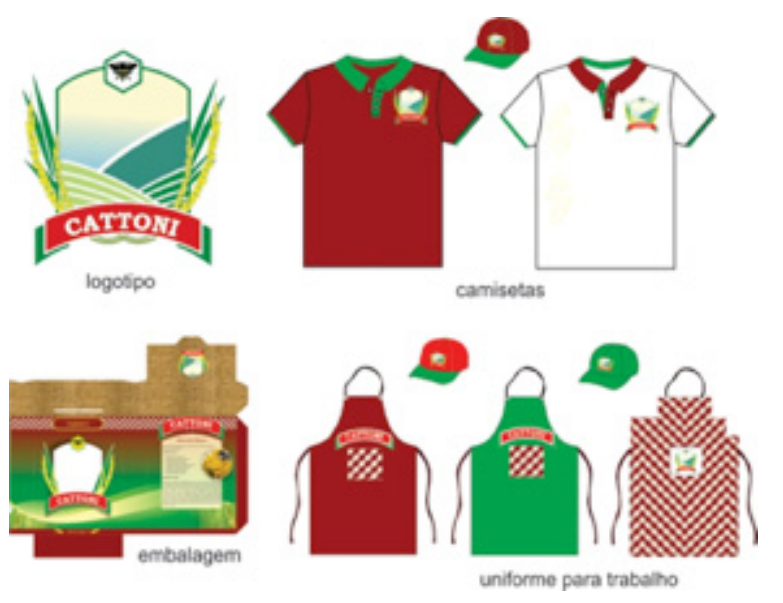

Figura 5 - Família Catonni, Agronômica/SC. Fonte: NASDESIGN (2013). 


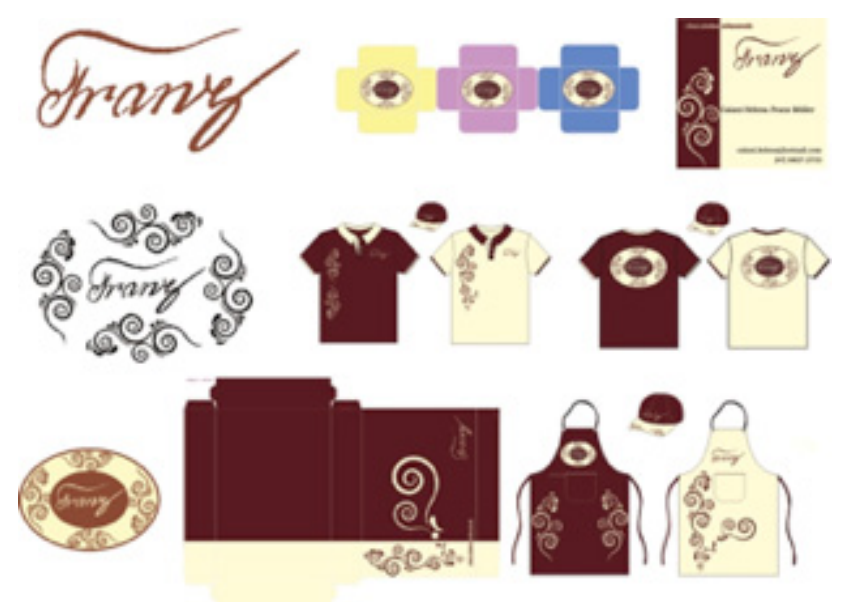

Figura 6 - Chocolate Franz, Trombudo Central/SC. Fonte: NASDESIGN (2013).

\section{Resultados obtidos}

A abordagem sistêmica está contribuindo para visualizar um panorama cada vez mais abrangente da gestão de design, entendendo a organização estudada como um sistema aberto, em que as interferências ou problemas detectados podem ser de ordem ambiental, social ou econômica, relativos a interferências e relações internas e externas à organização e ao sistema de gestão de design. Os atores sociais envolvidos, sendo esta uma pesquisa de ordem social, além da observação, têm sido uma importante fonte de informação para o delineamento de um panorama e para a avaliação da gestão de design extraindo informações cujos detalhes de ação somente quem está envolvido conhece. Os atores de pesquisa se classificam em clientes, fornecedores e colaboradores.

Por meio da observação participante, na etapa inicial e posterior coleta de dados através de entrevistas com os atores de pesquisa, obtiveram-se os resultados preliminares da pesquisa. Pela abordagem sistêmica da gestão de design nesta pesquisa, não houve restrições na busca de informações que explicitassem necessidades de áreas que, em princípio, não estariam obviamente relacionadas à gestão de design, mas que interferem nesse sistema, como problemas de estrutura e fatores de motivação profissional.

\begin{tabular}{|l|l|}
\hline \multicolumn{2}{|c|}{ Resultados preliminares da pesquisa da Gestão de Design com abordagem sistêmica } \\
\hline Gestão interna de projetos & $\begin{array}{l}\text { - Padronização das etapas de projeto } \\
\text { - Aperfeiçoamento de metodologia de distribuição de briefings } \\
\text { - Reunião de pauta com equipes setorizadas por tipo de projeto } \\
\text { - Criação de sistema de acompanhamento do projeto } \\
\text { - Aquisição/criação de sistema de gerenciamento de projetos com } \\
\text { controles de horas, datas, aviso de prazos, definição de } \\
\text { prioridades, }\end{array}$ \\
\hline Utilização de recursos & $\begin{array}{l}\text { - Melhor aproveitamento de recursos ambientais como separação } \\
\text { do lixo } \\
\text { - Redução de apresentação de projetos em material impresso } \\
\text { (utilização de recursos digitais) } \\
\text { - Criação de cultura junto ao cliente de desenvolvimento de } \\
\text { projetos mais voltados ao melhor uso de recursos ambientais, } \\
\text { econômicos e sociais } \\
\text { - Maior utilização de recursos de comunicação modernos, como } \\
\text { Skype, Twitter, redes de relacionamento, blogs etc. }\end{array}$ \\
\hline Serviços & $\begin{array}{l}\text { - Aumentar a divulgação na mídia dos serviços prestados } \\
\text { - Expansão e diversificação dos serviços }\end{array}$ \\
\hline
\end{tabular}




\begin{tabular}{|l|l|}
\hline Recursos humanos & $\begin{array}{l}\text { - Criação de planos de carreira } \\
\text { - Aumento nos valores de vales } \\
\text { - Agregação de mais um componente na equipe de criação }\end{array}$ \\
\hline Estrutura & $\begin{array}{l}\text { - Criação de espaço de laser } \\
\text { - Sala de reunião sem acesso ao setor de criação } \\
\text { - Diminuição do ruído no ambiente de trabalho } \\
\text { - Telefones fora da área de criação } \\
\text { - Separação do setor de desenvolvimento de internet e sistemas do } \\
\text { setor de criação }\end{array}$ \\
\hline $\begin{array}{l}\text { Relacionamento com } \\
\text { cliente }\end{array}$ & $\begin{array}{l}\text { - Inserção de sistema em que o cliente possa acompanhar o status } \\
\text { de seu projeto } \\
\text { - Padronização de atendimento telefônico } \\
\text { - Criação de formulários mais detalhados para tomada de briefing } \\
\text { junto ao cliente } \\
\text { - Formatação de orçamentos padrão } \\
\text { - Aumento da equipe de atendimento ao cliente }\end{array}$ \\
\hline Pós-venda & $\begin{array}{l}\text { - Maior preocupação com a satisfação do cliente após a } \\
\text { finalização dos projetos }\end{array}$ \\
\hline
\end{tabular}

Tabela 2 - Resultados preliminares. Fonte: autores

Pelas necessidades identificadas na tabela acima, na pesquisa preliminar pode-se perceber que, apesar de gestão de design ter o seu campo e estratégia de ação definidos, os fatores que influenciam para a sua boa execução podem vir das áreas mais diversas possíveis, desde a percepção externa de como os projetos são geridos até a forma como os colaboradores do processo de execução se sentem em relação às limitações de sua atuação, como a falta de uma área de lazer. São todas essas informações que se busca numa gestão de design com abordagem sistêmica, buscar essas relações que formam o sistema integral, os pontos em que as relações precisam ser fortalecidas e a formatação de novas relações nesse sistema formado pela gestão de design dentro da empresa.

\section{Conclusões}

Este projeto contribuiu de forma decisiva para a estruturação e o fortalecimento das pesquisas em Abordagem Sistêmica, Gestão de Design e Sustentabilidade no grupo de pesquisa NASDESIGN, o que consequentemente deve render outros estudos e possibilidades para outras empresas catarinenses.

No que se refere aos seus objetivos, considera-se que o projeto tenha os atingido, se não na sua totalidade ao menos na sua maioria, uma vez que se conseguiu obter, a partir dos estudos teóricos e dos experimentos práticos realizados, um melhor entendimento do potencial e das atuais limitações do uso dos modelos desenvolvido para aplicação no local.

Com este estudo oportunizou algumas necessidades tanto das MPEs como de pequenos empreendedores com potencial de seus produtos, com ênfase na quantificação da produções, assim como seus impactos ambientais, sociais e econômicos. 
Systemic approach to design in micro and small enterprises in the Alto Vale do Itajaí with a focus on innovation and sustainability

\section{Abstract:}

The systemic view of design contributes to design management processes becoming more sustainable. Sustainability is not only necessary, but a condition of the continuity and alignment of the profession with current concerns. In this context, the research had as objective to make a case study, evaluating the management of design in Micro and Small Enterprises of the Upper Valley of Itajaí, based on a systemic approach, with the purpose of orienting them towards sustainability and innovation. In order to do this, the intention was to carry out the research by doing an immersion in the context, collecting information through tools that allow the systemic view of the organizations. Through the results of research can be extracted the point indicators where the design management should become more sustainable and innovative within the small companies of Vale do Itajaí.

Keywords:

design; sustainability; Systemic approach; management; innovation.

\section{Referências bibliográficas}

ANDRADE, Aurélio L. et al. Pensamento sistêmico: caderno de campo: o desafio das mudanças sustentada nas organizações e na sociedade. Porto Alegre: Bookman, 2006.

AROS, Kammiri Corinaldesi. Elicitação do processo projetual do Núcleo de Abordagem Sistêmica do Design da Universidade Federal de Santa Catarina. Orientador: Luiz Fernando Gonçalves de Figueiredo - Florianópolis, SC, 2016.

BCSD PORTUGAL, Conselho Empresarial para o Desenvolvimento Sustentável. Inovação rumo ao desenvolvimento sustentável. Portugal: Young Managers Team, 2005.

CHIAVENATO, Idalberto. Introdução a teoria geral da administração. 4. ed. São Paulo: Makron Books, 1993.

DATSCHEFSKI, Edwin. The total beauty of sustainable products. Switzerland: Roto Vision, 2001.

KAZAZIAN, Thierry. Haverá a idade das coisas leves: design e desenvolvimento sustentável. São Paulo: Editora SENAC São Paulo, 2005.

KOLMODIN, Anne; PELLI, Aurora. Design for Innovation and Growth: a promising competitive concept in the future?. Östersund, Sweden: ITPS, 2005.

KRUCKEN, Lia. Design e território: valorização de identidades e produtos locais. São Paulo: Studio Nobel, 2009.

MANZINI, Ezio. Design para inovação social e sustentabilidade: comunidades criativas, organizações colaborativas e novas redes projetuais. Rio de Janeiro: E-Papers, 2008, 104p.

MANZINI, EZio; VEZZOLI, Carlo. O desenvolvimento de produtos sustentáveis: os requisitos ambientais dos produtos industriais. São Paulo: Edusp - Editora da Universidade de São Paulo, 2008.

OCDE - Organização de Cooperação e Desenvolvimento Econômico (2002) - Rumo a um desenvolvimento sustentável: indicadores ambientais. Tradução Ana Maria Teles, Salvador (Centro de Recursos Ambientais); Série Cadernos de referência ambiental; v.9, 244 p.

OGÊ, Marco; FIGUEIREDO, Luiz Fernando Gonçalves de. A prática sistêmica do design. Anais: Ensus 2009 - III Encontro de Sustentabilidade em Projeto do Vale do Itajaí. Itajaí: 2009.

VON STAM, Bettina. Managing innovation, design and creativity. 2.ed. Chichester, West 